University of Windsor

Scholarship at UWindsor

2013

\title{
By Librarians, For Librarians: Building a Strengths-Based Institute to Develop Librarians' Research Culture in Canadian Academic
} Libraries

\author{
Heidi LM Jacobs \\ University of Windsor \\ Selinda Adelle Berg \\ University of Windsor
}

Follow this and additional works at: https://scholar.uwindsor.ca/leddylibrarypub

Part of the Library and Information Science Commons

\section{Recommended Citation}

Jacobs, Heidi LM and Berg, Selinda Adelle. (2013). By Librarians, For Librarians: Building a StrengthsBased Institute to Develop Librarians' Research Culture in Canadian Academic Libraries. Journal of Academic Librarianship.

https://scholar.uwindsor.ca/leddylibrarypub/18

This Article is brought to you for free and open access by the Leddy Library at Scholarship at UWindsor. It has been accepted for inclusion in Leddy Library Publications by an authorized administrator of Scholarship at UWindsor. For more information, please contact scholarship@uwindsor.ca. 


\section{Accepted Manuscript}

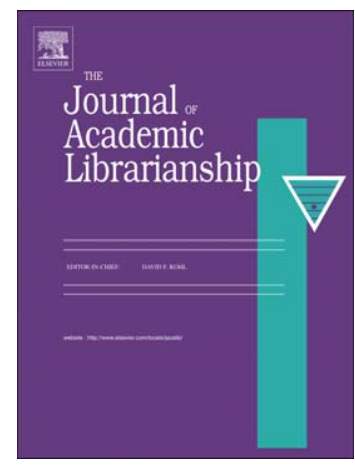

By Librarians, For Librarians: Building a Strengths-Based Institute to Develop Librarians' Research Culture in Canadian Academic Libraries

Heidi L.M. Jacobs, Selinda Adelle Berg

PII: $\quad$ S0099-1333(13)00018-9

DOI: doi: $10.1016 /$ j.acalib.2013.02.003

Reference: $\quad$ ACALIB 1402

To appear in: $\quad$ The Journal of Academic Librarianship

Received date: 12 December 2012

Accepted date: 12 February 2013

Please cite this article as: Heidi L.M. Jacobs, Selinda Adelle Berg, By Librarians, For Librarians: Building a Strengths-Based Institute to Develop Librarians' Research Culture in Canadian Academic Libraries, The Journal of Academic Librarianship (2013), doi: 10.1016/j.acalib.2013.02.003

This is a PDF file of an unedited manuscript that has been accepted for publication. As a service to our customers we are providing this early version of the manuscript. The manuscript will undergo copyediting, typesetting, and review of the resulting proof before it is published in its final form. Please note that during the production process errors may be discovered which could affect the content, and all legal disclaimers that apply to the journal pertain. 
By Librarians, For Librarians:

Building a Strengths-Based Institute to Develop Librarians' Research Culture in Canadian Academic Libraries

Heidi LM Jacobs (Corresponding Author)

\author{
Leddy Library
}

University of Windsor

401 Sunset Avenue, Windsor, Ontario, Canada N9B 3P4

hjacobs@uwindsor.ca

and

Selinda Adelle Berg

Leddy Library

University of Windsor Leddy Library

University of Windsor

401 Sunset Avenue, Windsor, Ontario, Canada N9B 3P4

sberg@uwindsor.ca 


\begin{abstract}
:
By Librarians, For Librarians:

Building a Strengths-Based Institute to Develop Librarians' Research Culture in Canadian Academic Libraries
\end{abstract}

In spite of the increase in formal and informal expectations for research by Canadian librarians, there have been few - if any - Canada-wide initiatives to help support librarians in meeting research expectations. Moreover, there have been few opportunities to address academic librarians' needs and Canadian librarian research culture in any systematic way, especially on a national scale. As a way of redressing these absences and filling this need, a four-day nation-wide institute was proposed and conducted in order to bring together Canadian librarians interested in developing their own research programs and working toward fostering a positive and productive research culture in Canadian academic libraries. This article describes the principles informing the institute's development and locates the institute's objectives within discussions of research culture, mentorship, and strengths-based approaches. 
By Librarians, For Librarians:

Building a Strengths-Based Institute to Develop Librarians' Research Culture in Canadian Academic Libraries

Introduction

A recent survey revealed that Canadian University Librarians and Deans noted "a significant shift" in research and scholarly expectations for Canadian academic librarians in the past 5 years and that they "expect the trend to continue into the future." (Berg, Jacobs, \& Cornwall, in press, p. 8) The Canadian Association of Research Libraries' (CARL) "Research Competencies for CARL Librarians" document describes how academic librarians "are increasingly required to conduct research in order to meet institutional service needs and to further their own careers" (CARL, 2007); the "Core Competencies for 21st Century CARL Librarians" document lists "research and contributions to the profession" as one of the seven core competencies" (CARL, 2010). In spite of the increase in formal and informal expectations for participation in research by Canadian librarians, there have been few — if any - Canada-wide initiatives to help support librarians in meeting research expectations. ${ }^{i}$ Moreover, there have been few opportunities to address academic librarians' needs and Canadian librarian research culture in any systematic way, especially on a national scale. To this end, we proposed and developed a four-day, nation-wide institute intended to bring together Canadian librarians interested in developing their own research programs and working toward 
fostering a librarian research culture in Canada. ${ }^{\text {ii }}$ The inaugural Librarians' Research Institute (LRI) was sponsored by CARL and held at the University of Windsor in June of 2012.

Many individual academic libraries in Canada and elsewhere have been looking to find meaningful and effective ways to support librarians in their research programs. The published literature reveals a few isolated and local efforts. Fennewald (2008), for example, explores the research productivity factors leading to publication by librarians at Penn State University. Schrader, Shiri, and Williamson (2012) describe the investigation of the "research learning needs of academic librarians employed by the University of Saskatchewan" so as to "facilitate development of an institutional framework for planning activities and programs designed to enhance the knowledge and skills of librarians as faculty about the various components of research and scholarly communication" (p. 148). These local efforts provide important supports to individual institutions; however, it is valuable to recognize that the broader issues librarians in Canada face are neither unique to individual institutions nor local in scope. The LRI was founded on the belief that much could be gained by pooling the strengths, expertise, and visions of librarians across Canada and forging and fostering relationships between librarians and institutions.

This article is not an evaluative assessment of the LRI itself but instead describes the principles that led to its development. ${ }^{\mathrm{iii}} \mathrm{We}$ also consider research culture within Canadian librarianship and argue for the need to nurture individual and national connections between librarians and advocate for building on the strengths we possess as professionals in order to foster a healthy research culture. Although our focus is on 
Canadian libraries, much of what is explored in this article is relevant to libraries across the globe. Before describing the principles of the LRI, we provide a brief overview of the LRI's development, objectives, planning structure and final form.

\section{The Development of the LRI}

The development of the LRI was informed by the published literature as well as informal and formal conversations with librarian colleagues and library administrators. We noted three recurrent assumptions in our profession's thinking about research and librarianship that we felt needed attention and unpacking. The first assumption was the primacy of deficits and barriers in discussions of Canadian librarians' research environments. In informal and formal conversations with our peers, we often heard statements about librarians and research that focused on deficits: "librarians lack the necessary research skills," "librarians do not have the required educational background to do research," and "librarians don't have a flexible workload" are three examples of recurrent deficit statements. The second assumption was that the ability to do research was commensurate with the possession of research skills. Underlying comments such as "librarians must know how to do statistics," "librarians don't know how to develop a strong research question," and "librarians need to know how to create an effective survey," reflect the assumption that if librarians were taught a fundamental research skill set they would be equipped to do research. The third assumption was an implied belief that to build research culture in Canadian libraries, expertise from beyond the walls of academic libraries and from beyond our national borders would have to be sought. Canadian and American library schools, American librarians, and non-librarian scholars were the most suggested sources of expertise that we should consider for guidance and assistance. 
In thinking critically about these three assumptions, we also noticed two muted yet persistent undercurrents that undermined their primacy. The first undercurrent was that in spite of the well-documented barriers to research activity, a significant number of highlyrespected Canadian academic librarians were producing high-caliber research and disseminating it nationally and internationally. If some librarians in Canada managed to produce high-quality scholarship in this barrier-filled environment, we wondered what strengths they had to help them navigate these barriers. Further, if Canadian librarians were producing high-caliber, internationally-respected research, should we not draw upon the experience, insight and expertise of these librarians and have them work as peer mentors to develop and guide the Institute's curriculum rather than seek expertise outside of the Canadian academic librarianship? The second undercurrent noted was that the prolific researchers we talked with informally did not see lack of skills as an insurmountable obstacle to their research. These researchers recognized that skills and methodologies are never fixed entities that, once learned, never evolve. They understood that research demands that scholars continually learn new skills or adapt their existing skills and methods depending on the research situation.

Significantly, the prolific researchers described struggles with intellectual isolation. Some librarians felt isolated because they were the only librarian doing research at their library whereas others were the only one doing research on a particular topic. The sense of isolation many expressed could not be ignored since almost all the librarians we talked to informally expressed a longing for connections with other researching librarians confronting similar issues. The librarians we talked to also described a need for time to reflect, think, explore, connect, and share. They needed conversation, encouragement, 
and support: in other words, they needed a research community. These undercurrents inspired and shaped the initial proposal for the LRI that was submitted to and accepted by CARL in the fall of 2011.

The Librarians' Research Institute

The ideas behind the LRI emerged from a confluence of conversations at several different times and locations. One such conversation was the CARL Research Libraries Committee's discussion about how they could actualize the core themes articulated in their 2010-2012 strategic planning document. ${ }^{\text {iv }}$ In particular, the Research Libraries Committee was considering concrete ways to develop research skills in research libraries and promote evidence-based librarianship. In the fall of 2011, we submitted a proposal to the Research Libraries Committee for a Librarians' Research Institute (LRI) that would be developed and delivered by Canadian academic librarians for Canadian academic librarians. The accepted proposal states, "At the core of this Institute is a belief that forging relationships with other librarian researchers is essential to developing and promoting Canadian librarians' research activities and forging a research infrastructure within CARL libraries." The LRI proposal goes on to describe the five objectives of the Institute:

- to provide practicing academic librarians in Canada opportunities to immerse themselves in sustained conversations and activities related to scholarly research, inquiry, and publishing;

- $\quad$ to provide librarians with an intensive workshop experience intended to take their current research projects to the next level as well as provide 
librarians with the opportunity to meet other researching librarians from across Canada;

- to provide Institute Peer mentors an opportunity to connect with other Canadian librarians with active, sustained research agendas;

- to allow each CARL library an opportunity to send at least one librarian to the inaugural offering of the Institute so that they may return to their home institution to share their knowledge and enthusiasm about research with their peers and colleagues;

- to work toward building an infrastructure for librarian researchers across Canada and for building a community of our own researchers in CARL libraries. This infrastructure and community will be built by CARL librarians for CARL librarians.

Once the proposal was accepted, two committees were created: a Planning Committee and a Program Committee. The Planning Committee was responsible for the selection of peer mentors, budgetary and sponsorship issues, and local arrangements while the Program Committee was responsible for content development and delivery. Members of these committees included a Planning Committee Chair, Educator Consultant, Peer Mentor Chair, Program Chair, CARL Liaison, and six peer mentors. Table 1 provides details about key positions and their role in the Librarians' Research Institute.

Because the Institute was sponsored by CARL, an element of national fairness was established in order to keep the Institute at its desired size and to allow representation from all CARL institutions. ${ }^{\mathrm{N}}$ Spots were reserved for one librarian from each CARL institution and University Librarians and Deans were asked to nominate one librarian to 
send. Any additional spots were awarded on the basis of a lottery. Twenty-nine librarians representing twenty-four of CARL's twenty-five English-language member institutions were represented, spanning more than 7500 kilometers across Canada. A formal evaluation process was administered and follow-up activities were planned for the twelve months after the Institute's completion.

\section{INSERT TABLE 2}

Principles of the LRI

Within the proposal for the LRI and the resulting curriculum, three principles provided the foundation for the LRI: focus on strengths not deficits; development of habits of mind not skills; and content created and delivered by librarians for librarians. These foundational principles informed our Institute's format, programming, and shortand long-term objectives.

\section{Strengths not Deficits}

Much of the literature about academic librarians' research in North America provides a comprehensive overview of the barriers that librarians confront while doing research. Fox's (2007) work on Canadian librarians underscores a need for a better understanding of librarians' workloads in relation to research time and the need for better administrative support. Powell, Baker, and Mika (2002) have articulated the major barriers librarians confront in terms of research: lack of time, inadequate education in research methods, lack of funding, and lack of institutional support. As we considered what could be done to help develop, nurture, and further the research work of academic 
librarians in Canada, we knew focusing only on deficits would mire our discussions on problems rather than solutions. Instead, we explicitly focused on the strengths our professional community possesses rather than what it lacks.

Considering alternatives to the deficit model, inspiration came from scholars, researchers, and practitioners in other fields who used strengths-based approaches. Emerging primarily from the field of social work, a strengths perspective, as articulated by Saleebey (1996),

demands a different way of looking at individuals, families, and communities. All must be seen in the light of their capacities, talents, competencies, possibilities, visions, values, and hopes, however dashed and distorted these may have become through circumstance, oppression, and trauma. The strengths approach requires an accounting of what people know and what they can do, however inchoate that may sometimes seem. It requires composing a roster of resources existing within and around the individual, family, or community. (p. 297)

Educational theorists have also developed and articulated a theory of strengths-based education that informed the development of the Institute. As Lopez and Louis (2009) describe, a strengths-based educational approach "is best understood as a philosophical stance and daily practice that shapes how an individual engages the teaching and learning process. Strengths-based educational models represent a return to basic educational principles that emphasize the positive aspects of student effort and achievement, as well as human strengths" (p. 1). Citing Clifton and Harter (2003) and Clifton and Nelson (1992), Lopez and Louis further describe how strengths-based education "presupposes 
that capitalizing on one's best qualities is likely to lead to greater success than would be possible by making a comparable investment of effort into overcoming personal weaknesses or deficiencies" (p. 2). Strengths-based approaches-though explicitly not about librarianship — offered language to conceptualize the LRI and its objectives.

The LRI was intended to help librarians consider themselves and their research activities, as Saleebey (1996) says, "in the light of their capacities, talents, competencies, possibilities, visions, values, and hopes" (p. 297). Further, it was important that participants and peer mentors do some "accounting" of "what they know and what they can do, however inchoate that may sometimes seem" and to compose a "roster of resources" existing within and around themselves and their community" (Saleebey, p. 297). By focusing the Institute on the strengths the participants and peer mentors possessed, we believed it was possible that we-as a community of librarian researchers - could do more than just navigate, negotiate, and survive obstacles: we could use our collective and individual strengths to explore new terrain and reach new heights.

\section{Habits of Mind not Skills}

From its inception, the LRI's mandate was to provide Canadian librarians with opportunities not otherwise available to them. For this reason, the LRI was specifically not a skills-based institute. The rationale for not hosting a skill-intensive workshop was fourfold. First, most MLIS degree programs in Canada have a required research methodologies course therefore we could assume most librarians coming to the LRI should have foundational understandings of LIS research methodologies and approaches. Second, many libraries in Canada had held the "Research Methods Workshop For 
Librarians" at their campuses so offering another skills-based program to Canadian librarians would be redundant. ${ }^{\mathrm{vi}}$ Third, it was anticipated that librarians from across the country would be coming with a range of backgrounds, a diverse pre-existing skill set, and unique questions related to their own research projects and agendas. Finally, as described above, we understood the learning of research skills to be a continual and iterative process wherein researchers are continually learning and relearning about methodologies, their uses and their applications. For these reasons, the focus of the LRI was not on skills but on developing researchers' habits of mind.

Focusing on habits of mind was a way to think about research as a holistic experience. Research draws on skills but it also requires the ability to solve problems, think critically and creatively, balance commitments, manage time, work with others, consider both the larger questions and the smaller details, and to communicate one's findings. In Discovering and Exploring Habits of Mind, Costa and Kallick (2000) describe sixteen habits of minds or "characteristics of what intelligent people do when they are confronted with problems, the resolutions to which are not immediately apparent" (p. 2). The habits of mind we find relevant for academic researchers include: persisting; thinking flexibly; responding with wonderment and awe; striving for accuracy; thinking about thinking (metacognition); creating, imagining and innovating; questioning and posing problems; applying past knowledge to new situations; remaining open to continuous learning; and thinking and communicating with clarity and precision. These habits of mind clearly could not be taught in a week, but the Institute could start to help librarians recognize and develop the habits of mind required to do the research they aspired to do. 
By librarians, for librarians

In the early stages of our LRI proposal writing, it had been thought that curriculum could be presented by scholar experts outside of the library community: data specialists, and professors of Sociology, LIS, and Composition topped the list of potential content providers as did experts from outside of Canada. It became apparent, however, that building a curriculum using experts outside of our discipline and country ran counter to the Institute's intentions. Relying upon non-librarians or non-Canadians for content and curriculum would do very little to develop and nurture a research culture among Canadian librarians. Looking to external experts also implied, inaccurately, that librarians across Canada did not have the expertise and background to teach and develop the LRI's curriculum. For these reasons, a peer mentor approach was proposed wherein accomplished Canadian librarian researchers would come together to build a curriculum that drew explicitly from their expertise and experience.

The proposal submitted to CARL in the fall of 2011 articulated a plan to have content developed and delivered by librarians in the capacity of peer mentors. The peer mentor model allowed both content developers and participants to benefit from the Institute. McDaugall and Beattie (1997) described the benefits of peer mentoring as "support, confidence building, mutual learning, different perspectives on issues, and the development of friendships...having a sounding board, motivation, networking, having a confidant(e), and stress management" (pp. 432-433). We saw the benefits of peer mentorship as useful components in building the community we saw as lacking in the Canadian academic librarianship. We also saw benefits of bringing peer mentors to the Institute from a range of institutions across Canada. Although there are examples of 
mentorship programs with a research component within individual libraries (Farmer, Stockholm \& Trussel, 2009; Keyse, Kraemer, \& Voelck, 2003; Kuyper-Rushing, 2001), there is added value to mentorship relationships outside of one's home institution since, as Freedman (2009) argues, building a mentor relationship with a mentor outside of one's own organization may help to ensure proper mentorship and avoid possible barriers related to authority and dependency (p. 174). To help further develop the hoped-for community, we determined that each participant would be assigned a peer mentor who would get to know that participant over the four days and who would maintain contact after the Institute to ensure that participants would continue to have some mentoring outside of their own institution.

After the proposal was accepted by CARL, there were concerns that there may not be sufficient expertise among Canadian academic librarians to use the peer mentor approach. Applications for peer mentors were solicited nationally and almost three times the anticipated applications were submitted. When the peer mentor applications were reviewed, the number of stellar applications from across the country quickly eradicated any doubt about the level of expertise among Canadian librarians. No one on the committee had quite anticipated the wealth of experience and breadth of expertise that Canadian librarians were eager to offer their colleagues: six of the seven chosen peer mentors held doctorates and three of the seven peer mentors held leadership positions in their libraries, and all of the peer mentors had an impressive publication record in the field of librarianship.

Peer mentors were chosen for their research achievements, leadership qualities, and the unique contributions they could make to a diverse team. The six peer mentors, the 
Peer Mentor Chair, the Program Chair, and the Educator Consultant made up the Program Committee. The Planning Committee gave the peer mentors full responsibility and autonomy to develop a curriculum that would meet the pre-defined outcomes of the Institute. Although the Educator Consultant was available to provide guidance to the peer mentors on curriculum development, pedagogical approaches, and overall vision of the LRI, the leaders of the Canadian Association of Research Libraries - the sponsoring organization - respected the peer mentors' abilities and expertise to develop a strong curriculum. The development of the curriculum by peer mentors from the Canadian community of academic libraries helped ensure that the content aligned with the needs and experiences of their colleagues.

The peer mentors initiated a survey of the participants to gauge their needs and interests and then from that survey identified four broad content areas to meet the objectives outlined by the developers and CARL Librarians Research Group. The four major components of the LRI curriculum were: balancing research and practice; research processes and planning; research approaches and methodologies; and dissemination and professional contribution. Table 3 provides an overview of the curriculum developed by the peer mentors. Peer mentors developed the curricular goals and objectives, created activities and learning scenarios, and found creative ways to draw upon and share the participants' experiences and expertise while helping to address their individual and collective needs. A fuller discussion of the curriculum will be made available in the program assessment but it is important to note that all aspects of the curriculum were driven by a desire to work toward actualizing our three guiding principles: to help develop participants' individual and collective strengths; to nurture research habits of 
mind; and to build on, share and develop the expertise the academic librarian community in Canada possesses.

\section{INSERT TABLE 3}

Conclusion: Toward the Creation of a Sharing, Reflective Research Community

Our previous research describes how academic libraries possess the four qualities that Walker, Golde, Jones, Bueschel, and Hutchings (2008) describe as vital to the development of strong intellectual cultures: a shared purpose; a diverse and multigenerational community; a flexible and forgiving community; and a respectful and generous community (Jacobs, Berg, \& Cornwall, 2010). In that article, we argued that one of librarianship's tremendous strengths is its community and its potential for building a strong intellectual culture. The Librarians' Research Institute offered Canadian librarians an opportunity to capitalize on the tremendous strengths we already possess. The Institute's three principles - a focus on strengths not deficits, habits of mind not skills, and internal not external expertise — were selected as a way for the Canadian academic library community to nurture the nascent qualities it possessed and to help develop a research community that is flexible and forgiving, respectful and generous. The inaugural Librarians' Research Institute brought Canadian librarians of all levels together to share our research experiences and to learn from our collective wisdom. 


\section{References}

Berg, S. A., Jacobs, H. L. M., \& Cornwall, D. (in press). Academic librarians and research: A study of Canadian library administrator perspectives. College \& Research Libraries. Retrieved from: http://crl.acrl.org/content/early/2012/06/19/crl12-366.full.pdf

Canadian Association of Research Libraries (CARL). (2007). Research Competencies for CARL Librarians. Retrieved from http://carlabrc.ca/uploads/pdfs/carl_lewg_product_brief-en.pdf

Canadian Association of Research Libraries (CARL). (2010). Core Competencies for 21st Century CARL Librarians, Retrieved from http://carlabrc.ca/uploads/pdfs/core_comp_profile-e.pdf

Costa, A. L., \& Kallick, B. (2000). Describing 16 habits of mind. Institute for Habits of Mind. Retrieved from http://www.instituteforhabitsofmind.com/resources/pdf/16HOM.pdf.

Farmer, D., Stockholm, M., \& Trussell, A. (2009). Revitalizing a mentoring program for academic librarians. College and Research Libraries, 70(1), 8-25.

Fennewald, J. (2008). Research productivity among librarians: Factors leading to publications at Penn State. College \& Research Libraries, 69(2), 104-116.

Fox, D. (2007). Finding time for scholarship: A survey of Canadian research university librarians. portal: Libraries and the Academy, 7(4), 451-462.

Freedman, S. (2009). Effective mentoring. IFLA Journal, 35(2), 171-182. 
Jacobs, H. L. M., Berg, S., \& Cornwall, D. (2010). Something to talk about: Re-thinking conversations on research culture in Canadian academic libraries. Partnership: The Canadian Journal of Library and Information Practice and Research,5(2).

Keyse, D., Kraemer, E. W., \& Voelck, J. (2003). Mentoring Untenured Librarians: All it Takes is a Little Un-TLC. College \& Research Libraries News, 64(6), 378-380.

Kuyper-Rushing, L. (2001). A formal mentoring program in a university library:

Components of a successful experiment. Journal of Academic Librarianship, 27(6), 440-446.

Lopez, S. J., \& Louis, M. C. (2009). The principles of strengths-based education. Journal of College and Character, 10(4), 1-8).

MacDaugall, M., \& Beattie, R. S. (1997) Peer mentoring at work: The nature and outcomes of non-hierarchical developmental relationships. Management Learning, 28(4), 423-237.

Powell, R. R., Baker, L. M., \& Mika, J. J. (2002). Library and information science practitioners and research. Library \& Information Science Research, 24(1), 49-72.

Saleebey, D. (1996). The strengths perspective in social work practice: Extensions and cautions. Social Work, 41(3), 41, no.3 (May 1996), 296-305.

Schrader, A. M., Shiri, A., \& Williamson, V. (2012). Assessment of the research learning needs of University of Saskatchewan librarians: A case study. College \& Research Libraries, 73(2), 147-163.

Walker, G. E., Golde, C. M., Jones, L., Bueschel, A. C., \& Hutchings, P. (2008). The formation of scholars: Rethinking doctoral education for the twenty-first century. San Francisco: Jossey-Bass. 


\section{TABLE 1}

\begin{tabular}{|c|c|c|}
\hline LRI Position & Professional Position & $\begin{array}{l}\text { LRI Committee } \\
\text { Membership }\end{array}$ \\
\hline $\begin{array}{l}\text { Planning Committee } \\
\text { Chair }\end{array}$ & $\begin{array}{l}\text { Dean of CARL-member library } \\
\text { - Chair of CARL Library Research } \\
\text { Group }\end{array}$ & Planning Committee \\
\hline $\begin{array}{l}\text { CARL Representatives } \\
\text { (2) }\end{array}$ & $\begin{array}{l}\text { Deans or Directors of CARL } \\
\text { member libraries } \\
\text { - Members of CARL Library } \\
\text { Research Group }\end{array}$ & Planning Committee \\
\hline Peer Mentor Chair* & $\begin{array}{l}\text { - Canadian academic librarian } \\
\text { - Facilitated and led Peer Mentor } \\
\text { Meetings } \\
\text { - Also an active Peer Mentor } \\
\text { - Original creator/ developer }\end{array}$ & $\begin{array}{l}\text { Planning Committee and } \\
\text { Program Committee }\end{array}$ \\
\hline Program Chair* & $\begin{array}{l}\text { - Canadian academic librarian } \\
\text { - Ensured that program aligned } \\
\text { with philosophical underpinnings } \\
\text { and intended objectives } \\
\text { - Original creator/ developer }\end{array}$ & $\begin{array}{l}\text { Planning Committee and } \\
\text { Program Committee }\end{array}$ \\
\hline Educator Consultant & $\begin{array}{l}\text { - Full professor at Canadian library } \\
\text { school } \\
\text { - LIS Educator } \\
\text { - Provided Program Committee } \\
\text { with pedagogical and curriculum } \\
\text { guidance }\end{array}$ & Program Committee \\
\hline Peer Mentors (7) & $\begin{array}{l}\text { - Accomplished researchers from } \\
\text { CARL-member libraries }\end{array}$ & Program Committee \\
\hline
\end{tabular}

- Authors of current article 
TABLE 2:

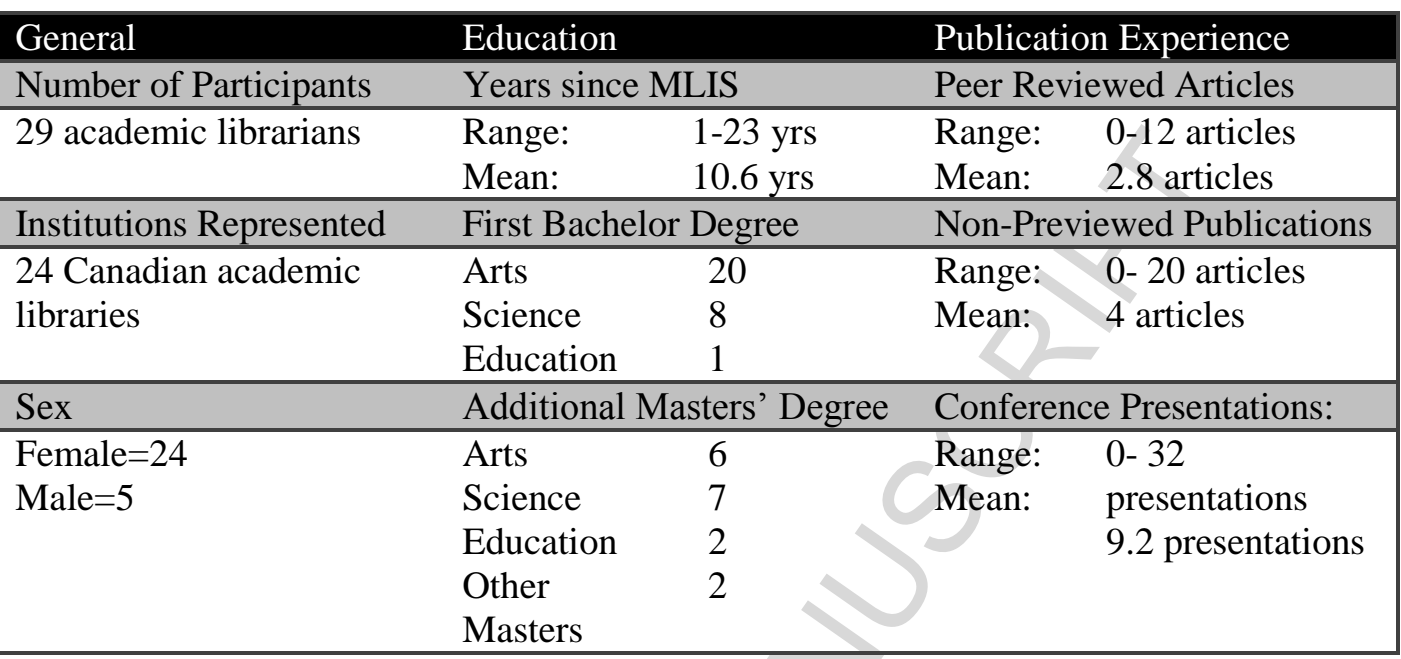

\section{TABLE 3}

\begin{tabular}{|c|c|}
\hline Components & Description \\
\hline $\begin{array}{l}\text { Balancing Research and } \\
\text { Practice }\end{array}$ & $\begin{array}{l}\text { - Explore the role of research in the work of academic } \\
\text { librarians, including how research can inform the } \\
\text { practice of academic librarianship } \\
\text { - Share practical considerations of how to manage both } \\
\text { the professional practice and research components of } \\
\text { academic librarians' work }\end{array}$ \\
\hline $\begin{array}{l}\text { Research Processe } \\
\text { Planning }\end{array}$ & $\begin{array}{l}\text { - Identify research goals (i.e., research trajectory) and } \\
\text { the research theme in research programs } \\
\text { - Discuss how to develop a Program of Research for } \\
\text { sustainable research throughout one's career }\end{array}$ \\
\hline $\begin{array}{l}\text { Research Approaches and } \\
\text { Methodologies }\end{array}$ & $\begin{array}{l}\text { - Explore methodologies conceptually and broadly. } \\
\text { - Recognize that method and research topic are deeply } \\
\text { interconnected parts of the research agenda and } \\
\text { therefore the topic and research methodology must } \\
\text { evolve together } \\
\text { - Recognize no one research methodology or approach } \\
\text { is perfect }\end{array}$ \\
\hline $\begin{array}{l}\text { Dissemination and } \\
\text { Professional Contribution }\end{array}$ & $\begin{array}{l}\text { Discuss the ways in which we share, contribute, and } \\
\text { exchange ideas about and explorations of our } \\
\text { profession } \\
\text { Consider how professional contributions can } \\
\text { facilitate research through activities such as } \\
\text { mentoring, editing, peer reviewing and conference } \\
\text { planning }\end{array}$ \\
\hline
\end{tabular}




\section{Footnotes}

i One current notable exception is the CARL Research in Librarianship Grants to "promote research in the field of academic librarianship by and/or about Canadians." These grants are intended to "support projects involving structured, evidence-based research, that propose answers to real-world issues." The scope of these grants, however, is fairly limited: only two grants of $\$ 2,000$ are awarded each year.

ii For this initial institute, we focused on academic librarians and, because of CARL's sponsorship, CARL member librarians. We envision that future iterations of the Institute will include all Canadian librarians with interests in research.

iii At writing, a formal evaluation of the LRI is being undertaken and results from these evaluations will be forthcoming.

iv The membership of the CARL Research Committee is upper administrators such as University Librarians, Deans, and Associate University Librarians. See "Canadian Association of Research Libraries Strategic Plan 2010-2012." Canadian Association of Research Libraries. August 29, 2012. http://carl-abrc.ca/strategic_plan.html.

v Currently, CARL is made up of 29 academic libraries (four of which are primarily French language institutions) and 3 National members (Library and Archives Canada, Library of Parliament and National Research Council-Canada Institute for Scientific and Technical Information). 
Libraries) offered one day workshops at a number of Canadian libraries. As described in promotional material, "This workshop is intended as an introductory to intermediate look at research methods, practices and strategies. Participants will learn tools and techniques for making the leap from interesting ideas to researchable topics, and from "how we done it good" reports to publishable research. The workshop will also touch on issues such as finding time to write, forming research teams, and working with colleagues from other disciplines." http://coppul.blogspot.ca/2009/09/workshop-announcement.html 